\title{
Accurate and Timely Identification of Genes Conferring Resistance to Carbapenems Serves as an Important Tool for Infection Control Measures
}

\author{
Priyadarshini Padaki ${ }^{1}$, Archa Sharma ${ }^{2} *$ and Kamal Sharma ${ }^{3}$ \\ ${ }^{1}$ Department of Microbiology, St.Johns Medical College, Bengaluru, India \\ ${ }^{2}$ Department of Microbiology, All India Institute of Medical Sciences, Bhopal, India \\ ${ }^{3}$ Department of Cardiology, U. N. Mehta Institute of Cardiology and Research Centre, \\ Ahmedabad, Gujarat, India, India \\ *Corresponding author
}

\begin{abstract}
A B S T R A C T
Gram negative enteric bacilli are a leading cause for sepsis in children and adults. The infections caused by Enterobacteriaceae are community and hospital-acquired. These bacteria have the potential to spread in the hospital environment and also across continents. Current study was designed to characterise Escherichia coli isolates from blood

Keywords

Carbapenems, Infection Control Measures, Multiplex PCR

Article Info

Accepted:

18 April 2018 Available Online: 10 May 2018 stream infection and identify the genes responsible for carbapenemase production and correlate the results with MHT. Ten consecutive isolates of $E$. coli resistant to imipenem $(10 \mu \mathrm{g}) /$ meropenem $(10 \mu \mathrm{g})$ isolated from individuals with blood stream infection were selected for testing. Among the 10 isolates tested, 4 were positive with MHT. Among these, 3 of them harboured the genes for carbapenemase production as detected by PCR. This included 1 NDM, 1 IMP and 1 OXA-48 genes. Three of the isolates which tested negative with MHT were found to be positive for the NDM gene by PCR thus giving a false negative result with MHT. However, a total of 2 isolates were negative for the genes mentioned above thus giving a false positive result with MHT. Three isolates gave a negative result with MHT among which 2 of them did not have any of the carbapenemase genes by PCR. A total of 4 out of 10 isolates gave a positive result with PCR for the genes tested. The most common gene conferring resistance to carbapenems for $E$. coli in the study was NDM (3 out of 10 isolates). We found one isolate each positive for IMP and OXA-48 genes. We conclude that accurate and timely identification of genes conferring resistance to carbapenems serves as an important tool in instituting therapy and infection control measures. Conventional multiplex PCR is a sensitive technique to detect multiple genes.
\end{abstract}

\section{Introduction}

The prime cause for sepsis in children and adults are gram negative enteric bacilli (1)(2)(3). The infections caused by Enterobacteriaceae are community and hospital-acquired. These bacteria have the potential to spread in the hospital environment and also across continents (4). Irrational use of antibiotics coupled with rapid emergence of drug resistance in bacteria is a major problem faced by health care setting around the world 
(5). Carbapenemase is one of the beta lactamases conferring resistance to carbapenem group of drugs making it difficult to treat since the treatment options are lesser. Detection of mechanisms of resistance to carbapenems plays an important role in understanding the epidemiology and spread of resistance. This further helps to develop policies for antimicrobial therapy and surveillance (11).

Current primary study was designed to characterise Escherichia coli isolates from blood stream infection and identify the genes responsible for carbapenemase production and correlate the results with MHT. Multiplex PCR was performed to detect various genes responsible for carbapenemase production that are NDM, KPC, SPM, VIM, OXA-48, IMP and GES and compared with the MHT results.

\section{Materials and Methods}

Ten consecutive isolates of E. coli resistant to imipenem $(10 \mu \mathrm{g}) /$ meropenem $(10 \mu \mathrm{g})$ isolated from individuals with blood stream infection were selected for testing. Antimicrobial susceptibility results of these isolates were interpreted according to CLSI breakpoints (6). These isolates were retrieved for further characterisation with MHT and molecular detection of various genes.

Modified Hodge test (MHT) was performed on all the isolates. A $0.5 \mathrm{Mc}$ Farland broth of E. coli ATCC 25922 in saline was prepared, diluted 1 in 10 and inoculated on Mueller Hinton Agar plate as lawn culture. Ertapenem disk $(10 \mu \mathrm{g})$ was placed in the centre of the plate. Three to five colonies of the test strain and positive (known strain of Klebsiella pneumoniae producing KPC) control strains were streaked perpendicular to the disk starting from the edge of the disk to the periphery. The plate was incubated at $37^{\circ} \mathrm{C}$ for 16-20 hours. An enhanced growth of lawn culture around the streak at the intersection of the streak and zone of inhibition (clover leaf pattern) was considered a positive test (6).

Conventional multiplex PCR was performed on all the 20 isolates irrespective of the results of the MHT. Separate clean rooms were used extraction of DNA and PCR reaction and the amplicons were visualised on agarose gel in a third room to avoid contamination. Positive control strains for PCR were obtained. (Courtesy IMHA.inc, Chicago). PCR grade water was used as the negative control. Controls were included with every run of the PCR. The test isolates and control strains were grown on blood agar plates and identification of colonies confirmed with preliminary screening media and biochemical reactions. Five to six similar looking colonies were selected and inoculated into $2 \mathrm{ml}$ of sterile saline. The tubes were vortexed, placed on a heating block at $100^{\circ} \mathrm{C}$ for 10 minutes and centrifuged. The extracted DNA was used for the PCR reactions.

Multiplex PCR was performed in two separate reactions; reaction 1 (SPM, KPC, OXA-48 and VIM) and reaction 2 (NDM, GES and IMP). Primers were obtained from (Sigma Aldrich, Bengaluru). The protocols used were according to those in the references shown in the table 1. Amplification was done in VERITI 96 well Thermal cycler (Applied Biosystems, CA, USA) using the following conditions; 1 cycle at $95^{\circ} \mathrm{C}$ for 15 minutes, 30 cycles of denaturation, annealing and extension at $94^{\circ} \mathrm{C}$ for 30 seconds, $59^{\circ} \mathrm{C}$ for 90 seconds and $72^{\circ} \mathrm{C}$ for 90 seconds and a final extension of 1 cycle at $72^{\circ} \mathrm{C}$ for 10 minutes.

Amplicons were visualized in a $2 \%$ agarose gel containing ethidium bromide under UV light using the Gel Doc XR (Bio-Rad, Hercules, CA, USA). The bands obtained for individual isolates were compared with the bands obtained for the control strains. 


\section{Results and Discussion}

Among a total of 10 isolates, all were resistant to both imipenem and meropenem by disk diffusion screening test. The rates of resistance for other antimicrobials were as follows; $99 \%$ for cefpodoxime, cefaperazone/ sulbactam, piperacillin/ tazobactam, 92\% for gentamicin, 54\% for amikacin and netilmicin. However, all the isolates were susceptible to colistin and tigecycline.

Among the 10 isolates tested, 4 were positive with MHT. Among these, 3 of them harboured the genes for carbapenemase production as detected by PCR. This included 1 NDM, 1
IMP and 1 OXA-48 genes. Three of the isolates which tested negative with MHT were found to be positive for the NDM gene by PCR thus giving a false negative result with MHT. However, a total of 2 isolates were negative for the genes mentioned above thus giving a false positive result with MHT. Three isolates gave a negative result with MHT among which 2 of them did not have any of the carbapenemase genes by PCR. A total of 4 out of 10 isolates gave a positive result with PCR for the genes tested. The most common gene conferring resistance to carbapenems for E. coli in the study was NDM (3 out of 10 isolates). We found one isolate each positive for IMP and OXA-48 genes.

Table.1 Results obtained in the study for carbapenem resistant isolates by MHT and molecular characterisation for various genes using multiplex PCR and the possible mechanisms of resistance

\begin{tabular}{|c|c|c|c|c|}
\hline & $\begin{array}{c}\text { No. of } \\
\text { samples } \\
\text { positive with } \\
\text { MHT }\end{array}$ & $\begin{array}{l}\text { No. of } \\
\text { samples } \\
\text { negative } \\
\text { for MHT }\end{array}$ & Remarks & References \\
\hline $\begin{array}{l}\text { No. of samples positive for } \\
\text { NDM gene }\end{array}$ & 1 & 3 & $\begin{array}{l}\text { False negative MHT could be due to low } \\
\text { sensitivity in detecting carbapenemase } \\
\text { producers harbouring the NDM gene }\end{array}$ & (6) \\
\hline $\begin{array}{l}\text { No. of samples positive for } \\
\text { IMP gene }\end{array}$ & 1 & - & \multirow{2}{*}{$\begin{array}{l}\text { The test has better sensitivity for OXA- } 48 \\
\text { and KPC producing organisms. } \\
\text { In this study we found that MHT was } \\
\text { positive for two isolates which were positive } \\
\text { for OXA- } 48 \text { and IMP genes. }\end{array}$} & (14) \\
\hline $\begin{array}{l}\text { No. of samples positive for } \\
\text { OXA- } 48 \text { gene }\end{array}$ & 1 & - & & \\
\hline $\begin{array}{l}\text { No. of samples negative for } \\
\text { PCR }\end{array}$ & - & - & $\begin{array}{l}\text { False positive MHT could be due to excess } \\
\text { production of ESBL's by organisms which } \\
\text { tends to give a resistant zone when tested } \\
\text { with carbapenems since these enzymes have } \\
\text { a weak activity against carbapenems }\end{array}$ & (11) (13) \\
\hline $\begin{array}{l}\text { No. of samples negative for } \\
\text { PCR }\end{array}$ & - & 4 & $\begin{array}{l}\text { Resisance to carbapenems by disk } \\
\text { diffusion but negative with both PCR and } \\
\text { MHT could be due to porin loss (OMP } \\
\text { defects which do not allow the antibiotic to } \\
\text { enter the cell); efflux pumps which leads to a } \\
\text { reduced concentration of the antimicrobial } \\
\text { agent within the bacterial cell; production of } \\
\text { Amp C beta lactamase production (which } \\
\text { was not tested for in the current study) }\end{array}$ & (12) \\
\hline Total & 4 & 7 & & \\
\hline
\end{tabular}


Carbapenemases are a versatile group of $\beta$ lactamases that are characterised by their resistance to virtually all $\beta$-lactam antibiotics, including the cephalosporins and carbapenems. These resistant isolates are coresistant to other classes of drugs like fluoroquinolones, aminoglycosides and cotrimoxazole. There are three important classes of carbapenemases Ambler Class A serine beta lactamases (KPC, SME, NMC-A, IMI, PER, GES, SFO, SFC, IBC), Class B metallo beta lactamases (VIM, GIM, SIM, NDM, IMP, SPM) and Class C oxacillinases (OXA, PSE) (11).

Any isolate giving a resistant zone size with the screening test which is the disk diffusion test with imipenem/meropenem $(10 \mu \mathrm{g})$ should be subjected to a genotypic or phenotypic confirmatory test (11). These tests are important since there are various mechanisms conferring resistance to carbapenems. Phenotypic tests detect the various classes of carbapenemases and include the following. Modified Hodge Test detects the presence of all carbapenemases. But there are fallacies associated with MHT in that it is less sensitive for detection of isolates harbouring the NDM gene (6).

Better assays have been developed known as inhibitor based disk diffusion assays for various resistance mechanisms such as metallobetalactamases, KPC and Amp C beta lactamases. All metallo beta-lactamases are inhibited by dipicolinic acid, KPC is inhibited by boronic acid but not by cloxacillin and Amp C is inhibited by both boronic acid and cloxacillin (Neo-Sensitabs, Rosco Diagnostica, Denmark). Not all resistant mechanisms can be detected by phenotypic tests. Conventional multiplex PCR is a rapid and sensitive method for the same (15). A multiplex format carries the advantage of giving an accurate result of detecting multiple genes at the same time (10).
Molecular assays are more expensive than inhibitor based disk diffusion tests but are more sensitive. Molecular characterisation is necessary to detect the genes responsible for conferring resistance in particular geographic areas. NDM is the most prevalent in the Indian subcontinent (12). KPC is spread worldwide (12). Hence in the current study we characterized the genes responsible for conferring resistance to carbapenems in E.coli isolates. We compared the results with MHT and found several discrepancies. NDM was the common gene conferring resistance. However, we found that among a total of 6 isolates positive for the NDM gene, 4 of them gave a false negative result with MHT. The reason for this is a well known fact that MHT has a low sensitivity of $11 \%$ in detecting carbapenemase producers harbouring the NDM gene while it performs better for OXA48 and KPC producing organisms (6)(14). In this study we found that MHT was positive for the isolates which were positive for OXA48 and IMP genes thus strengthening the fact that MHT performs poorly with organisms harbouring the NDM gene.

Among the 20 isolates, 3 gave a false positive result with MHT. The reasons could be excess production of ESBL's. These false positive results can be expected in our set up where the prevalence of ESBL's is rampant especially with the organism E. coli. Since these enzymes have a weak activity against carbapenems, they tend to give a resistant zone when tested with carbapenems (11)(13).

We found that a majority of isolates ( 9 out of 20) were negative with PCR and MHT though they had a resistant zone with carbapenems. The reasons for this could be other resistant mechanisms such as porin loss (OMP defects) and efflux pumps which reduce the concentration of antimicrobials within the bacterial cell. One more reason could be production of Amp $\mathrm{C}$ beta lactamase 
production (which was not tested for in the current study).

We conclude that accurate and timely identification of genes conferring resistance to carbapenems serves as an important tool in instituting therapy and infection control measures. Conventional multiplex PCR is a sensitive technique to detect multiple genes (15). Phenotypic tests can serve as an inexpensive alternative when molecular techniques cannot be used.

\section{References}

1. Viswanathan $\mathrm{R}$, Singh AK, Basu $\mathrm{S}$, Chatterjee S, Sardar S, Isaacs D. Multi-drug resistant gram negative bacilli causing early neonatal sepsis in India. Arch. Dis. Child. Fetal Neonatal Ed. 2012 May; 97(3): F182-187.

2. Kang C-I, Kim S-H, Park WB, Lee K-D, Kim H-B, Kim E-C, et al. Bloodstream infections caused by antibiotic-resistant gram-negative bacilli: risk factors for mortality and impact of inappropriate initial antimicrobial therapy on outcome. Antimicrob. Agents Chemother. 2005 Feb;49(2):760-6.

3. Adams-Sapper S, Sergeevna-Selezneva J, Tartof S, Raphael E, Diep BA, Perdreau-Remington F, et al. Globally dispersed mobile drug-resistance genes in gram-negative bacterial isolates from patients with bloodstream infections in a US urban general hospital. J. Med. Microbiol. 2012 Jul; 61(Pt 7):968-74.

4. Nordmann P, Naas T, Poirel L. Global spread of Carbapenemase-producing Enterobacteriaceae. Emerging Infect. Dis. 2011 Oct; 17(10):1791-8.

5. Zhang R, Cai J-C, Zhou H-W, Nasu M, Chen G-X. Genotypic characterization and in vitro activities of tigecycline and polymyxin $\mathrm{B}$ for members of the Enterobacteriaceae with decreased susceptibility to carbapenems. J. Med. Microbiol. 2011 Dec;60(Pt 12):18139.

6. Clinical and Laboratory Standards Institute. Performance Standards for Antimicrobial Susceptibility Testing; Twenty third informational supplement. M100-S23 ed. Wayne,PA,USA; 2013

7. Ellington MJ, Kistler J, Livermore DM, Woodford N. Multiplex PCR for rapid detection of genes encoding acquired metallo-beta-lactamases.

$\mathrm{J}$.

Antimicrob. Chemother. 2007 Feb;59(2):321-2.

8. Yigit H, Queenan AM, Anderson GJ, Domenech-Sanchez A, Biddle JW, Steward CD, et al. Novel carbapenemhydrolyzing beta-lactamase, KPC-1, from a carbapenem-resistant strain of Klebsiella pneumoniae. Antimicrob. Agents Chemother. 2001 Apr; 45(4):1151-61.

9. Poirel L, Dortet L, Bernabeu S, Nordmann P. Genetic features of blaNDM-1positive Enterobacteriaceae. Antimicrob. Agents Chemother. 2011 Nov;55(11):5403-7.

10. Dallenne C, Da Costa A, Decré D, Favier C, Arlet G. Development of a set of multiplex PCR assays for the detection of genes encoding important betalactamases in Enterobacteriaceae. J. Antimicrob. Chemother. 2010 Mar;65(3):490-5.

11. Cohen Stuart J, Leverstein-Van Hall MA. Guideline for phenotypic screening and confirmation of carbapenemases in Enterobacteriaceae. Int. J. Antimicrob. Agents. 2010 Sep; 36(3): 205-10.

12. Nordmann P, Dortet L, Poirel L. Carbapenem resistance in Enterobacteriaceae: here is the storm! 
Trends Mol Med. 2012 May;18(5):263-72.

13. Carvalhaes CG, Picão RC, Nicoletti AG, Xavier DE, Gales AC. Cloverleaf test (modified Hodge test) for detecting carbapenemase production in Klebsiella pneumoniae: be aware of false positive results. J Antimicrob Chemother. 2010 Feb 1;65(2):249-51.

14. Girlich D, Poirel L, Nordmann P. Value of the Modified Hodge Test for Detection of Emerging
Carbapenemases

in Enterobacteriaceae. J Clin Microbiol. 2012 Feb;50(2):477-9.

15. Monteiro J, Widen RH, Pignatari ACC, Kubasek C, Silbert S. Rapid detection of carbapenemase genes by multiplex real-time PCR. J Antimicrob Chemother. 2012 Jan 9; dkr563.

16. Queenan AM, Bush K. Carbapenemases: the versatile beta-lactamases. Clin. Microbiol. Rev. 2007 Jul;20(3):440458.

\section{How to cite this article:}

Priyadarshini Padaki, Archa Sharma and Kamal Sharma. 2018. Accurate and Timely Identification of Genes Conferring Resistance to Carbapenems Serves as an Important Tool for Infection Control Measures. Int.J.Curr.Microbiol.App.Sci. 7(05): 2574-2579.

doi: https://doi.org/10.20546/ijcmas.2018.705.296 